\title{
Exploring the relation between learning style and cognitive impairment in patients with acquired brain injury
}

\author{
Citation for published version (APA):
}

Boosman, H., Visser-Meily, J. M. A., Post, M. W. M., Lindeman, E., \& van Heugten, C. M. (2012). Exploring the relation between learning style and cognitive impairment in patients with acquired brain injury. Neuropsychological Rehabilitation, 22(1), 26-39. https://doi.org/10.1080/09602011.2011.632907

\section{Document status and date: \\ Published: 01/01/2012}

DOI:

10.1080/09602011.2011.632907

\section{Document Version:}

Publisher's PDF, also known as Version of record

\section{Document license:}

Taverne

\section{Please check the document version of this publication:}

- A submitted manuscript is the version of the article upon submission and before peer-review. There can be important differences between the submitted version and the official published version of record. People interested in the research are advised to contact the author for the final version of the publication, or visit the DOI to the publisher's website.

- The final author version and the galley proof are versions of the publication after peer review.

- The final published version features the final layout of the paper including the volume, issue and page numbers.

Link to publication

\footnotetext{
General rights rights.

- You may freely distribute the URL identifying the publication in the public portal. please follow below link for the End User Agreement:

www.umlib.nl/taverne-license

Take down policy

If you believe that this document breaches copyright please contact us at:

repository@maastrichtuniversity.nl

providing details and we will investigate your claim.
}

Copyright and moral rights for the publications made accessible in the public portal are retained by the authors and/or other copyright owners and it is a condition of accessing publications that users recognise and abide by the legal requirements associated with these

- Users may download and print one copy of any publication from the public portal for the purpose of private study or research.

- You may not further distribute the material or use it for any profit-making activity or commercial gain

If the publication is distributed under the terms of Article $25 \mathrm{fa}$ of the Dutch Copyright Act, indicated by the "Taverne" license above, 


\title{
Neuropsychological Rehabilitation
}

\section{Exploring the relation between learning style and cognitive impairment in patients with acquired brain injury}

\author{
H. Boosman , J. M. A. Visser-Meily , M. W. M. Post , E. Lindeman \& C. M. Van \\ Heugten
}

To cite this article: H. Boosman , J. M. A. Visser-Meily , M. W. M. Post , E. Lindeman \& C. M. Van Heugten (2012) Exploring the relation between learning style and cognitive impairment in patients with acquired brain injury, Neuropsychological Rehabilitation, 22:1, 26-39, DOI: 10.1080/09602011.2011.632907

To link to this article: https://doi.org/10.1080/09602011.2011.632907

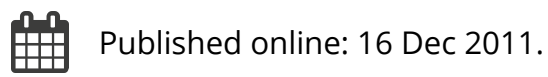

Submit your article to this journal $\widetilde{\pi}$

凹 Article views: 481

Q View related articles $\sqsubset$

Citing articles: 1 View citing articles 


\title{
Exploring the relation between learning style and cognitive impairment in patients with acquired brain injury
}

\author{
H. Boosman ${ }^{1}$, J. M. A. Visser-Meily ${ }^{1}$, M. W. M. Post ${ }^{1,2}$, \\ E. Lindeman', and C. M. Van Heugten ${ }^{3}$ \\ ${ }^{1}$ Rudolf Magnus Institute of Neuroscience and Centre of Excellence for \\ Rehabilitation Medicine, University Medical Centre Utrecht and \\ De Hoogstraat, Utrecht, The Netherlands \\ ${ }^{2}$ Swiss Paraplegic Research, Nottwil, Switzerland \\ ${ }^{3}$ Maastricht University Medical Centre (MUMC), Department of Psychiatry \\ and Neuropsychology, School for Mental Health and Neuroscience, \\ Maastricht, The Netherlands; Maastricht University, Department of \\ Neuropsychology and Psychopharmacology, Maastricht, The Netherlands
}

The way a patient prefers to approach or choose a learning situation represents the patient's learning style. The objective of this chart review study was to explore the relation between learning style and cognitive impairment in patients with acquired brain injury (ABI). We used data from files of 92 adult patients with ABI referred to inpatient rehabilitation, who completed the Adapted Learning Style Inventory (A-LSI) and at least one of the following neuropsychological tests: Trail Making Test, Rey Auditory Verbal Learning Test, WAIS-III Digit Span, Rey-Osterrieth Complex Figure Test-Copy, Stroop Color-Word Test,

Correspondence should be addressed to C. M. Van Heugten, Maastricht University School for Mental Health and Neuroscience, Department of Psychiatry and Neuropsychology P.O. Box 616, 6200 MD Maastricht, The Netherlands. E-mail: c.vanheugten@np.unimaas.nl

All authors participated in the concept and design of the study. $\mathrm{HB}, \mathrm{AVM}, \mathrm{CvH}$, and MP performed the analysis and interpretation of the data and drafted and revised the manuscript. All authors are responsible for the reported research and have approved the manuscript as submitted.

This project is part of the research program Cognitive Rehabilitation which is funded by the National Initiative on Brain and Cognition in The Netherlands (NWO number 056-11-014).

Special thanks to Lisette Meijer, Klaartje Verhoeven, Corine Werkhoven, Joke Heins, Bianca van Oossanen and Roos Sevat for providing the files.

(C) 2012 Psychology Press, an imprint of the Taylor \& Francis Group, an Informa business http://www.psypress.com/neurorehab http://dx.doi.org10.1080/09602011.2011.632907 
or the Brixton Spatial Anticipation Test. The A-LSI yielded the following distribution of learning styles: 4 doers, 48 observers, 2 deciders and 38 thinkers. No significant correlation coefficients were found between the neuropsychological tests and the A-LSI. Furthermore, Chi-square tests revealed no significant associations between learning style (observer, thinker) and cognitive impairment. The results of this exploratory study suggest that learning style and cognitive impairment are independent in patients with ABI.

Keywords: Learning; Education; Brain Injuries; Cognition; Therapy.

\section{INTRODUCTION}

Patients with acquired brain injury (ABI) frequently experience enduring cognitive impairments which can interfere with the process of rehabilitation and can negatively affect the patient's quality of life (QoL) (Nys et al., 2006). In response to these problems, cognitive rehabilitation has emerged as a method to remediate or alleviate cognitive impairments as well as behavioural, emotional and social disabilities, and to maximise the level of independence and QoL (Brouwer, van Zomeren, Berg, Bouma, \& de Haan, 2002; Wilson, 2000). There is a large body of literature concerning cognitive interventions and their effectiveness (Bowen \& Lincoln, 2007; Cicerone et al., 2005; Nair \& Lincoln, 2007; Park \& Ingles, 2001; Rasquin et al., 2010; Rees et al., 2007; Rohling, Faust, Beverly, \& Demakis, 2009; Tsaousides \& Gordon, 2009), in which three general approaches can be distinguished: substitution of intact functions, direct retraining, and teaching of compensatory strategies (Wilson, 2008). Whichever approach is used, it should be recognised that they all include aspects of (re)learning. In fact, the process of learning is important for all facets of rehabilitation.

Although learning is a fundamental component of rehabilitation, relatively little is known about learning processes after ABI. In clinical practice, neuropsychological measures can be used to detect cognitive impairments that might influence a patient's learning process during rehabilitation. For instance, impairments in memory, attention, and executive functioning, are likely to thwart the learning of new skills or strategies. However, neuropsychological measures mainly provide information about the limitations that a patient has, and does not give profound insight into a patient's learning strengths and preferences.

The way a person prefers to approach or choose a learning situation represents a person's "learning style" (Cassidy, 2004; Smits, Verschuren, Ketelaar, \& Van Heugten, 2010). Currently, little is known about learning styles of patients with ABI. The implementation of learning style in rehabilitation is still in its infancy and a validated learning style instrument for patients 
with ABI has not yet been developed (Cassidy, 2004; Smits et al., 2010). The available learning style measures were developed for educational purposes, for instance within the field of health, management, and academic settings (Cassidy, 2004). It is unknown whether these instruments are also feasible for patients with ABI.

One of the most influential learning style measures is Kolb's Learning Style Inventory (LSI) (Kolb \& Kolb, 2005). The LSI is based on Kolb's Experiential Learning Theory (ELT; Kolb \& Kolb, 2005) which considers learning to be a continuous and interactive process. It has been suggested that the ELT is associated with certain brain structures (Zull, 2002). For instance, active experimentation is said to be related to the motor brain, and abstract conceptualisation is said to involve the frontal integrative cortex. If indeed an association between learning style and brain structures exists, it becomes interesting to investigate what influence impairments in the brain may have on a person's learning style.

A previous study speculated that impairments in certain cognitive functions following brain injury can possibly cause difficulties in rehabilitation because of a decreased ability to learn in the preferred way (Fujii, 1996). This would imply that, for instance, an impairment regarding abstract reasoning would provide a greater barrier for a patient who has an abstract learning style than for a patient who learns through trial-and-error (Fujii, 1996). Fujii explored the association between Kolb's learning styles and cognitive skills in healthy individuals and reported an association between the decider and observer learning style and strong verbal reasoning.

After exploring the relationship between learning style and cognitive functions in healthy individuals, a next step would be to explore whether there is an association between learning style and cognitive impairment in patients with ABI. Therefore, the objective of this exploratory study was to determine whether learning style is associated with specific cognitive impairments in patients with ABI.

\section{METHODS}

\section{Participants}

For this chart review study, we considered files of adult patients with ABI who were consecutively referred to inpatient rehabilitation in rehabilitation centre De Hoogstraat (The Netherlands) between February 2008 and January 2011. At De Hoogstraat, all patients are informed that their files can be used anonymously for research purposes, unless they object.

We included patients with ABI who completed the Adapted Learning Style Inventory (A-LSI) and a neuropsychological assessment (NPA) as part of routine assessment including at least one of the following neuropsychological 
tests: Trail Making Test, Rey Auditory Verbal Learning Test, WAIS-III Digit Span, Rey-Osterrieth Complex Figure Test-Copy, Stroop Color-Word Test, or the Brixton Spatial Anticipation Test. Scores on the A-LSI and neuropsychological tests were collected from the files, as were demographic data, ABI characteristics and the Barthel Index (Wade \& Collin, 1988) score at admission to the rehabilitation centre.

\section{Procedure}

The NPA and A-LSI were completed independently during the diagnostic phase, within approximately 6 weeks of admission. The Adapted Learning Style Inventory (A-LSI; Akkerman, 2003) has already been used in clinical practice in our rehabilitation centre for several years. The cognition therapist completed and interpreted the A-LSI together with the patient within a onehour session. The amount of assistance given while completing the A-LSI was dependent upon the patient's physical (e.g., fatigue, visual impairments) and cognitive functioning (e.g., neglect, attention deficits). The assistance could consist of, for example, clarifying the individual items, reading the questions aloud, or providing more structure by showing the answers one at a time on separate cards. In case of neglect, a perpendicular vertical line was drawn as a cue to the neglected side. The results were discussed with the patient after approximately one week. Based on the A-LSI result and observations during completion of the test, the cognition therapist wrote a report with individually tailored learning advice for all involved disciplines.

\section{Measures}

Disability. The Barthel Index is a measure of severity of disability. It has a $0-20$ range for which a higher score reflects better functioning.

Learning style assessment. The A-LSI is a modified version of Kolb's Learning Style Inventory (LSI; Kolb \& Kolb, 2005). In contrast to Kolb's LSI, the modified version includes questions about concrete situations such as, for instance, learning how to sail a boat. The items of Kolb's LSI are stated more generally (e.g., I learn by: doing, watching, thinking, feeling). Therefore, the A-LSI seems more appropriate for use in brain injury rehabilitation than Kolb's LSI. Since the A-LSI version was originally developed for college students, items have been slightly changed into age-appropriate questions. The translated items are shown in the Appendix.

The A-LSI is based on Kolb's Experiential Learning Theory (ELT; Kolb \& Kolb, 2005). According to this model, effective learning depends on four learning modes (1) concrete experience (CE) - doing something and discovering its consequences, (2) reflective observation (RO) - watch what happens and think about it, (3) abstract conceptualisation (AC) - talk with 
others and apply existing knowledge, and (4) active experimentation (AE) test theories and carry out plans.

The A-LSI contains nine items each with four answers corresponding to these four learning modes: CE, AC, AE, and RO. Participants were asked to rank the answers by giving 1, 2, 3 or 4 points in which 4 points represents the most suitable answer and 1 point the least suitable answer. The items belonging to the same mode are summed. For each mode, three items are not included in the sum-scores which leaves sum scores ranging from 6 to 24. These four scores can be used to calculate two dimensions of learning: prehension (AC minus $\mathrm{CE}$ ) and transformation (AE minus $\mathrm{RO}$ ). Prehension is the act of grasping information from experience (abstract versus concrete) and transformation is the processing of this information (active versus reflective). Relative positioning along these two dimensions defines a preference for one of the following four learning styles: doer, observer, decider, or thinker (Figure 1).

Neuropsychological assessment. From the routine neuropsychological assessment, we used neuropsychological tests for the following four major cognitive domains: attention, memory, perception and executive functioning. For the attention domain we chose the Trail Making Test (TMT; Reitan, 1956) parts $\mathrm{A}$ and $\mathrm{B}$. Part A is a reaction-time measure of psychomotor speed and part B of divided attention. A higher score reflects a worse condition.

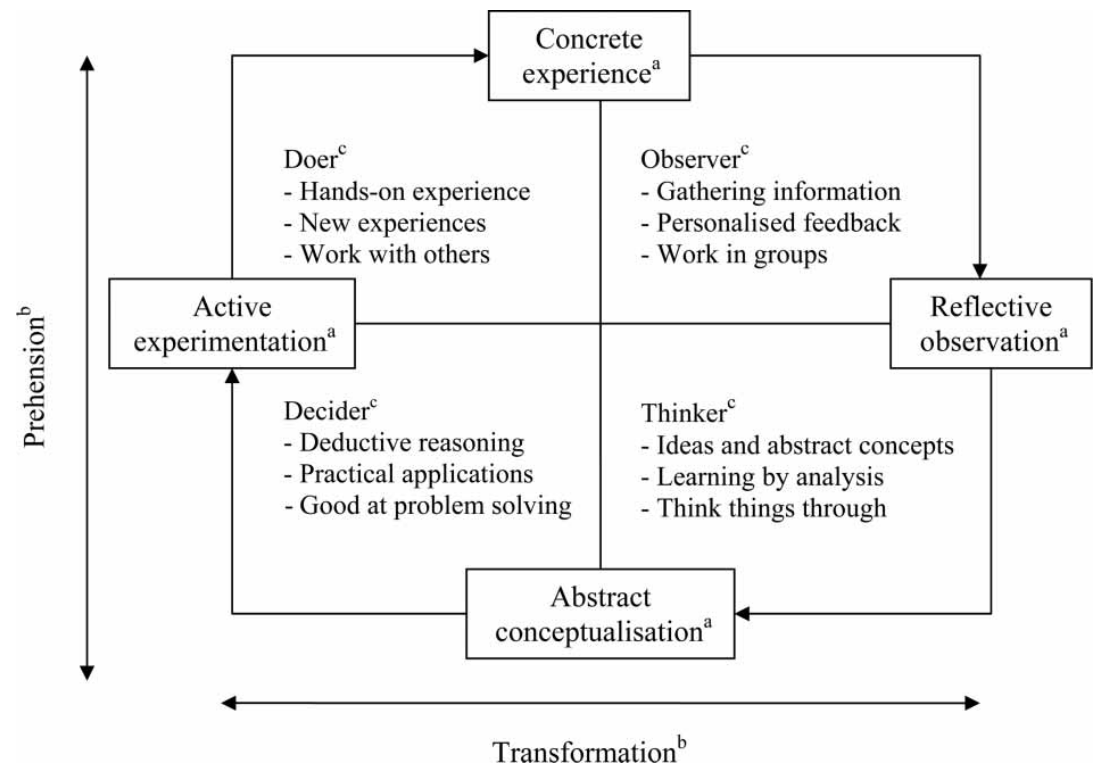

Figure 1. Learning styles and matching learning preference (Kolb \& Kolb, 2005). 
To determine memory functions we chose the Rey Auditory Verbal Learning Test (RAVLT; Rey, 1958) and the Wechsler Adult Intelligence Scale (WAIS) - III Digit Span (Wechsler, 2001). The RAVLT is a verbal memory task that determines immediate recall on five consecutive learning trials (range 0-75), delayed recall (range 0-15) and delayed recognition (range $0-30$ ). The WAIS-III Digit Span is a measure of working memory and attention with a $0-30$ range.

The Rey-Osterrieth Complex Figure Test-Copy (ROCFT; Osterrieth, 1944) was chosen for the perception domain. The ROCFT measures visuoconstruction, organisational ability and planning. The total score ranges from $0-36$.

For the executive domain, we chose the Stroop Color-Word Test (Stroop, 1935) and the Brixton Spatial Anticipation Test (Burgess \& Shallice, 1997). The Stroop Color-Word Test is a measure of speed of information processing and response inhibition. The degree of interference was calculated with the following formula: Stroop III $=([$ Stroop I + Stroop II $] / 2)$. The Brixton measures rule detection and concept shifting. The number of errors are noted with a $0-55$ range. In both the Stroop Color-Word Test and the Brixton a higher score reflects a worse condition. The tests are described in more detail elsewhere (Lezak, Howieson, \& Loring, 2004). Dutch norms were used when available.

\section{Statistical analysis}

NPA and A-LSI data were first presented using descriptive statistics. The association between learning modes and dimensions and raw neuropsychological test scores were investigated by means of Spearman correlations with Bonferroni correction for multiple comparisons. Spearman correlations were considered significant when $p<.006$. Correlation coefficients between .30 and .50 were considered moderate and correlations exceeding .50 strong (Cohen, 1988). Next, neuropsychological test scores were dichotomised into impaired or not impaired. Scores were considered impaired when greater than or equal to the following cut-off values: 10th percentile, 1st decile, or 6th Wechsler Scale (Lezak, Howieson, \& Loring, 2004, p.142). Chi-square tests with continuity correction were used to determine whether there is an association between the four learning styles and the dichotomous test scores. Alpha was set at .05. Data were analysed using SPSS version 18.0.

\section{RESULTS}

\section{Participants}

In total, 92 patients with $\mathrm{ABI}$ were included. The majority of patients suffered a stroke $(79.3 \%)$. At admission to the rehabilitation centre, the mean Barthel Index score was $15.0(S D=4.7)$ indicating moderate disability. Table 1 
TABLE 1

Characteristics of the study sample $(n=92)$

\begin{tabular}{lc}
\hline Gender, $\%$ female $(n)$ & $37.0 \%(34)$ \\
Mean age in years $(S D)$ & $55.6(14.6)$ \\
$\quad$ Range & $18-84$ \\
High education ${ }^{\mathrm{a}}(n=90), \%(n)$ & $38.9 \%(35)$ \\
Diagnosis, $\%(n)$ & \\
$\quad$ Ischaemic stroke & $55.4 \%(51)$ \\
Haemorrhagic stroke & $16.3 \%(15)$ \\
Subarachnoid haemorrhage & $7.6 \%(7)$ \\
Post-anoxic brain damage & $5.4 \%(5)$ \\
Traumatic brain injury & $12.0 \%(11)$ \\
Brain abscess & $1.1 \%(1)$ \\
Brain tumour & $2.2 \%(2)$ \\
NPA: mean time post-admission in days $(S D)(n=89)$ & $37.7(38.8)$ \\
A-LSI: mean time post-admission in days $(S D)(n=67)$ & $40.8(42.8)$ \\
Barthel Index, mean $(S D)$ & $15.0(4.7)$ \\
\hline
\end{tabular}

\footnotetext{
${ }^{\mathrm{a}}$ High education $\geq$ finished high school; Low education $<$ finished high school. NPA $=$ Neuropsychological assessment.
}

presents the sample characteristics. The mean time between admission to the rehabilitation centre and administration of the A-LSI was 40.8 days ( $S D=$ $42.8)$, and of the NPA 37.7 days $(S D=38.8)$.

\section{Learning style and cognitive impairment}

In part of the files we could only trace back the total A-LSI score and not the scores for the individual items. Therefore, learning style classifications could be made for 92 patients and scores for the learning modes and dimensions were available for 63 patients. In total, 4 patients were doers, 48 were observers, 2 deciders, and 38 thinkers (Table 2). Cognitive impairments were most frequently observed for attention $(40.8 \%-49.4 \%)$ and concept shifting (40.9\%) (Table 3). Spearman correlations between the four learning modes and two dimensions with the nine raw neuropsychological test scores were calculated. No significant correlation coefficients were found. Furthermore, Chi-square tests indicated no significant association between the observer and thinker learning style and cognitive impairment (Table 4). Differences between the other learning styles were not assessed due to the small number of patients.

\section{DISCUSSION}

In this retrospective, exploratory study we evaluated the extent to which cognitive impairment is related to learning style in patients with ABI. The 
TABLE 2

Descriptive statistics A-LSI

\begin{tabular}{lcccc}
\hline & Range & Mean $(\mathrm{SD})$ & Median & IQR \\
\hline Modes $(n=63)$ & & & & \\
Concrete experience & $8-22$ & $14.1(3.3)$ & 14.0 & 5.0 \\
Reflective observation & $11-21$ & $16.0(2.5)$ & 16.0 & 4.0 \\
Abstract conceptualisation & $10-22$ & $16.6(2.7)$ & 16.0 & 4.0 \\
Active experimentation & $10-22$ & $14.5(2.3)$ & 14.0 & 3.0 \\
Dimensions $(n=63)$ & & & & \\
Prehension AC-CE & $-10-12$ & $2.5(4.7)$ & 3.0 & 6.0 \\
Transformation AE-RO & $-10-10$ & $-1.6(4.0)$ & -1.0 & -4.0 \\
\hline & Doer & Observer & Decider & Thinker \\
\hline Learning style $(n=92)$ & $4.3 \%(4)$ & $52.2 \%(48)$ & $2.2 \%(2)$ & $41.3 \%(38)$ \\
\hline
\end{tabular}

majority of patients in our sample had an observer or thinker learning style. These two groups did not differ in terms of neuropsychological impairment. Furthermore, no associations were found between learning style and neuropsychological tests.

TABLE 3

Descriptive statistics neuropsychological tests

\begin{tabular}{|c|c|c|c|c|c|c|}
\hline \multirow[b]{2}{*}{ Neuropsychological test } & \multicolumn{5}{|c|}{ Raw scores } & \multirow{2}{*}{$\begin{array}{c}\% \\
\text { impaired }^{c}\end{array}$} \\
\hline & $n$ & Range & Mean $(S D)$ & Median & $I Q R$ & \\
\hline Trail Making Test - Part $\mathrm{A}^{\mathrm{a}}$ & 79 & $18-322$ & $76.1(64.8)$ & 50.0 & 53.0 & 49.4 \\
\hline Trail Making Test - Part $\mathrm{B}^{\mathrm{a}}$ & 71 & $43-905$ & $\begin{array}{c}167.9 \\
(144.2)\end{array}$ & 111.0 & 129.0 & 40.8 \\
\hline RAVLT Immediate recall & 82 & $4-70$ & $36.0(12.1)$ & 35.0 & 14.5 & 23.2 \\
\hline RAVLT Delayed recall & 80 & $0-14$ & $6.1(3.8)$ & 6.0 & 6.0 & 33.8 \\
\hline RAVLT Recognition & 80 & $15-30$ & $26.7(3.6)$ & 28.0 & 5.0 & \\
\hline WAIS-III Digit Span & 59 & $7-21$ & $13.4(3.1)$ & 13.0 & 5.0 & 25.4 \\
\hline ROCFT Copy & 45 & $20.5-36$ & $32.6(3.8)$ & 34.0 & 3.0 & 20.0 \\
\hline Stroop Color-Word Test ${ }^{\mathrm{a}, \mathrm{b}}$ & 78 & $13.5-475.5$ & $67.8(61.2)$ & 55.3 & 36.0 & 14.1 \\
\hline $\begin{array}{l}\text { Brixton Spatial Anticipation } \\
\text { Test }^{\mathrm{a}}\end{array}$ & 22 & $4-45$ & $19.4(10.3)$ & 17.0 & 13.8 & 40.9 \\
\hline
\end{tabular}

RAVLT $=$ Rey Auditory Verbal Learning Test; WAIS-III $=$ Wechsler Adult Intelligence Scale-III; ROCFT $=$ Rey-Osterrieth Complex Figure Test.

${ }^{\text {a }}$ Higher score reflects worse condition.

${ }^{\mathrm{b}}$ Stroop III $=([$ Stroop I + Stroop II] / 2).

${ }^{\mathrm{c}}$ Impairment: score $\leq 10$ th percentile, 1st decile or 6th Wechsler Scale.

${ }^{\mathrm{d}}$ No available cut-off point. 
TABLE 4

Comparison of dichotomous test scores for the observer and thinker learning style

\begin{tabular}{|c|c|c|c|c|c|}
\hline \multirow[b]{2}{*}{ Neuropsychological test } & \multicolumn{2}{|r|}{ Observer } & \multicolumn{2}{|r|}{ Thinker } & \multirow[b]{2}{*}{$p^{\mathrm{a}}$} \\
\hline & $N$ & $\%$ impaired $(n)$ & $n$ & $\%$ impaired $(n)$ & \\
\hline Trail Making Test - A & 42 & $50.0(21)$ & 31 & $51.6(16)$ & 1.0 \\
\hline Trail Making Test - B & 39 & $48.7(19)$ & 27 & $33.3(9)$ & .32 \\
\hline RAVLT immediate recall & 44 & $22.7(10)$ & 34 & $23.5(8)$ & 1.0 \\
\hline RAVLT delayed recall & 42 & $35.7(15)$ & 34 & $35.3(12)$ & 1.0 \\
\hline RAVLT recognition ${ }^{\mathrm{b}}$ & 42 & - & 34 & - & - \\
\hline WAIS-III digit span & 33 & $27.3(9)$ & 24 & $20.8(5)$ & .81 \\
\hline ROCFT Copy & 25 & $28.0(7)$ & 18 & $11.1(2)$ & .34 \\
\hline Stroop Color-Word Test & 41 & $9.8(4)$ & 32 & $18.8(6)$ & .44 \\
\hline Brixton Spatial Anticipation Test & 14 & $35.7(5)$ & 8 & $50.0(4)$ & .84 \\
\hline
\end{tabular}

RAVLT $=$ Rey Auditory Verbal Learning Test; WAIS-III $=$ Wechsler Adult Intelligence Scale-III; ROCFT $=$ Rey-Osterrieth Complex Figure Test.

${ }^{\mathrm{a}} \mathrm{Chi}$-square with continuity correction.

${ }^{\mathrm{b}}$ No available cut-off point.

A previous study among healthy individuals (Fujii, 1996) did report an association between Kolb's learning styles and cognitive functions. In our ABI population no such association was found. A possible explanation for the lack of an association in our study might be that we used different neuropsychological tests and an adapted version of Kolb's LSI. Use of other neuropsychological tests or another learning style instrument would possibly have produced different results. Another possibility could be that patients first need to experience their cognitive impairments before they are able to adopt a more efficient learning style. Therefore, it is possible that an association will be found in the long term when patients are no longer in inpatient rehabilitation. However, for clinical practice we believe that it is important to determine the patient's learning styles at the start of rehabilitation so that therapists can tailor rehabilitation to the individual.

A possible explanation for the uneven distribution of learning styles might be that learning styles change following ABI. Unfortunately, no studies have been executed in which the influence of $\mathrm{ABI}$ on learning styles was investigated. There is also no information regarding the distribution of learning styles in the general population, therefore it remains unclear whether the four learning styles are also unequally represented in the general population. Another possible explanation is that the A-LSI is not a valid measure to assess learning styles. Further studies are needed to determine the reliability and validity of the A-LSI in an ABI population.

Several limitations of this study should be noted. First, the A-LSI was originally developed for students; information concerning the development and 
validation of the A-LSI was not available. It remains to be seen whether it is possible and sensible to utilise an instrument in rehabilitation that was originally developed for use in education. However, given the exploratory nature of this study, we considered it important to start with evaluating an existing learning style instrument to gain familiarity and experience with learning style in rehabilitation before developing a model for rehabilitation.

Second, the question remains as to whether it is possible to use a selfassessment instrument in this population. Completing the A-LSI requires relatively intact cognitive functions and some degree of introspection. Furthermore, it is not suitable for patients with severe aphasia.

Furthermore, due to the retrospective nature of this study, the content of the neuropsychological assessment varied as well as the frequency with which the different tests were used. In addition, it should be kept in mind that use of other neuropsychological tests or another learning style instrument would possibly have produced different results.

Further research into learning style is recommended to increase our understanding of learning style post-ABI and the added value for rehabilitation. Longitudinal studies are needed to, for instance, track potential changes in learning style following $\mathrm{ABI}$.

In conclusion, the current exploratory study provides no support for the association between learning style and cognitive impairment. To our knowledge, this is the first study that attempts to explore the association between learning style and cognition in an ABI population. Therefore, caution should be taken in interpreting these preliminary findings. Further research into learning style and cognition is needed to verify these results and determine the added value of learning style assessment in ABI rehabilitation.

\section{REFERENCES}

Akkerman, B. (2003). Leerstijlentest Kolb/Akkerman. Retrieved from http://www. brandwonden.nl/download/146 (accessed October 11, 2010).

Bowen, A., \& Lincoln, N. B. (2007). Cognitive rehabilitation for spatial neglect following stroke. Cochrane Database of Systematic Reviews, 18(2), CD003586.

Brouwer, W., van Zomeren, E., Berg, I., Bouma, A., \& de Haan, E. (Eds.) (2002). Introduction. In Cognitive rehabilitation. A clinical neuropsychological approach (pp. 7-20). Amsterdam, The Netherlands: Boom.

Burgess, P., \& Shallice, T. (1997). The Hayling and Brixton Tests. Test manual. Bury St Edmunds, UK: Thames Valley Test Company.

Cassidy, S. (2004). Learning styles: An overview of theories, models, and measures. Educational Psychology, 24(4), 419-444.

Cicerone, K. D., Dahlberg, C., Malec, J. F., Langenbahn, D. M., Felicetti, T., Kneipp, S., et al. (2005). Evidence-based cognitive rehabilitation: Updated review of the literature from 1998 through 2002. Archives of Physical Medicine and Rehabilitation, 86(8), 1681-1692. 
Cohen, J. (1988). Statistical power analysis for the behavioural sciences (2nd ed.). Hillsdale, NJ: Lawrence Erlbaum Associates.

Fujii, D. E. (1996). Kolb's learning styles and potential cognitive remediations of brain-injured individuals: An exploratory factor analysis study. Professional Psychology: Research and Practice, 27(3), 266-271.

Kolb, A. Y., \& Kolb, D. A. (2005). The Kolb Learning Style Inventory - Version 3.1, 2005 Technical Specifications. Retrieved from http://www.learningfromexperience.com (accessed September 9, 2010).

Lezak, M., Howieson, D., \& Loring, D. (2004). Neuropsychological assessment (4th ed.). New York, NY: Oxford University Press.

Nair, R. D., \& Lincoln, N. B. (2007). Cognitive rehabilitation for memory deficits following stroke. Cochrane Database of Systematic Reviews, 18(3), CD002293.

Nys, G. M., van Zandvoort, M. J., van der Worp, H. B., de Haan, E. H., de Kort, P. L., Jansen, B. P., \& Kappelle, L. J. (2006). Early cognitive impairment predicts long-term depressive symptoms and quality of life after stroke. Journal of the Neurological Sciences, 247(2), 149-156.

Osterrieth, P. A. (1944). Filetest de copie d'une figure complex: Contribution a l'etude de la perception et de la memoire [The test of copying a complex figure: A contribution to the study of perception and memory]. Archives De Psychologie, 30, 286-356.

Parente, R., Stapleton, M. C., \& Wheatley, C. J. (1991). Practical strategies for vocational reentry after traumatic brain injury. Journal of Head Trauma Rehabilitation, 6(3), 35-45.

Park, N. W., \& Ingles, J. L. (2001). Effectiveness of attention rehabilitation after an acquired brain injury: A meta-analysis. Neuropsychology, 15(2), 199-210.

Rasquin, S. M., Bouwens, S. F., Dijcks, B., Winkens, I., Bakx, W. G., \& Van Heugten, C. M. (2010). Effectiveness of a low intensity outpatient cognitive rehabilitation programme for patients in the chronic phase after acquired brain injury. Neuropsychological Rehabilitation, 20(5), 760-777.

Rees, L., Marshall, S., Hartridge, C., Mackie, D., Weiser, M., \& Erabi Group (2007). Cognitive interventions post acquired brain injury. Brain Injury, 21(2), 161-200.

Reitan, R. (1956). Trail Making Test: Manual for administration, scoring and interpretation. Bloomington, IN: Indiana University.

Rey, A. (1958). L'Examen Clinique en Psychologie. Paris, France: Press Universitaire de France.

Rohling, M. L., Faust, M. E., Beverly, B., \& Demakis, G. (2009). Effectiveness of cognitive rehabilitation following acquired brain injury: A meta-analytic re-examination of Cicerone et al.'s $(2000,2005)$ systematic reviews. Neuropsychology, 23(1), 20-39.

Smits, D. W., Verschuren, O., Ketelaar, M., \& Van Heugten, C. (2010). Introducing the concept of learning styles in rehabilitation. Journal of Rehabilitation Medicine, 42(7), 697-699.

Stroop, J. (1935). Studies in interference in serial verbal reactions. Journal of Experimental Psychology, 18, 643-662.

Tsaousides, T., \& Gordon, W. A. (2009). Cognitive rehabilitation following traumatic brain injury: Assessment to treatment. Mount Sinai Journal of Medicine, New York, 76(2), 173-181.

Wade, D. T., \& Collin, C. (1988). The Barthel ADL Index: A standard measure of physical disability? International Disability Studies, 10(2), 64-67.

Wechsler, D. (2001). WAIS-III Nederlandstalige bewerking. Afname en Scoringshandleiding. Lisse, The Netherlands: Swets \& Zeitlinger.

Wilson, B. A. (2000). Compensating for cognitive deficits following brain injury. Neuropsychology Review, 10(4), 233-243.

Wilson, B. A. (2008). Neuropsychological rehabilitation. Annual Review of Clinical Psychology, $4,141-162$. 
Zull, J. E (2002). The art of changing the brain: Enriching teaching by exploring the biology of learning. In A. Y. Kolb \& D. A. Kolb (Eds.), The Kolb Learning Style Inventory - Version 3.12005 Technical Specifications. Sterling, VA: Stylus. Retrieved from http://www. learningfromexperience.com.

Manuscript received March 2011 Revised manuscript received October 2011

First published online December 2011 
APPENDIX

Translated items of the A-LSI

\begin{tabular}{|c|c|c|}
\hline Concrete experience & Reflective observation & Abstract conceptualisation \\
\hline \\
\hline $\begin{array}{l}\text { A: I would directly step into the } \\
\text { boat and try to sail. }\end{array}$ & $\begin{array}{l}\text { B: I would stay on the shore first, } \\
\text { observing others. }\end{array}$ & $\begin{array}{l}\text { C: I would first look up in a book how to } \\
\text { sail. }\end{array}$ \\
\hline
\end{tabular}

2. You get a new computer. You want to use it immediately. What do you do?

$\begin{array}{lll}\text { A: I would first think about } & \text { B: I would first ask about all its } & \text { C: I would first read the manual. } \\ \text { everything I can do with it. } & \text { functions and what I can do with it. }\end{array}$

3. You put together a piece of furniture. What do you do?

A: I would first verify what I have B: I would read the manual

to do and determine the best

completely and take a close look at

C: I would first check what I can use the way to do it. the building plan. piece of furniture for.

4. You hear a story about an exciting event and you want to tell the story at home. What do you do?
A: I would imagine that the
B: I love what I am hearing and I want
to witness the exciting event for
$\mathrm{C}$ : I first want to know whether the story is exciting event is currently correct.

happening and that I'm present.

5. You are going on holiday. You choose out of two countries. What do you do?

A: I would imagine what I could $\quad$ B: I would not think too long. You
do in these countries. I find it
have to make the best of it. hard to choose.

6. You are going to buy a new bicycle. What do you do?

A: I would think about where I

could go with the bicycle and

how much fun it would be.
B: I would want to know exactly the C: I would want to try the new bicycle
specifications, which one is the best and the prices.
C: I would try to get to know as much as possible about the countries. Afterwards I would decide.
Active experimentation

D: I would ask someone to demonstrate it.

D: I would try out everything immediately.

D: I would immediately start putting the piece of furniture together.

D: I would just repeat the story.

D: I would consider what would be the best for me. I am a quick decider.

D: I would consider which bicycle is most suitable for me. 
7. You have an exam. What do you do?

A: I would only learn what I need B: I would try to understand the to know for the exam. learning material.

8. Someone offers you a new job. What do you do?

A: I would try to imagine what it B: I would first want to know exactly would be like for me to do th job

how hard I have to work and how much money I earn.
C: I would write down the most important things.

C: I would want to know exactly what someone has to do in the company and how the company works.

9. You are attending a course and you can decide about the way of teaching. What do you do?

A: I would want the professor to B: I would want to work on projects. C: I would want to receive concrete tell stories.
D: I learn, just because I need to.

D: I would go to work and then experience whether I like it or not.

D: I would like to know why I have to do certain assignments.

The grey-coloured answers are not included in the sum-scores. 